\title{
Static analysis of tall buildings based on Timoshenko beam theory
}

\author{
Seyed Mozafar Davari ${ }^{1} \cdot$ Mohsen Malekinejad $^{1,2}$ (]) Reza Rahgozar $^{3}$
}

Received: 1 May 2019 / Accepted: 30 September 2019 / Published online: 29 October 2019

(c) The Author(s) 2019

\begin{abstract}
In this paper, the continuum model, which is known as Kwan model, has been presented for the analysis of tall buildings that have been as an appropriate approximation of the overall behavior of the structure. Tall building was modeled as a cantilever beam and analyzed with the assumption of flexural behavior based on Euler-Bernoulli Beam Theory, then the displacement of floors was calculated. o consider the shear lag effects in the overall displacement of the structure, Timoshenko's beam model has been considered and related relations were extracted. The lateral displacement formulas obtained and calculated for the framed tube system modeled by Kwan's method. To verify the results, numerical models were created in software (ETABS) and statically were analyzed for lateral loading. Finally the results were compared with those obtained by computer analysis and the corresponding diagrams were presented. At the end, the shape factor formula has been developed to improve the results of the Timoshenko's theory.
\end{abstract}

Keywords Framed tube system · Equivalent continuous method · Euler-Bernoulli beam theory · Timoshenko's beam theory

\section{Introduction}

Tall buildings are a logical and economical solution for the settlement of the population, jobs, departments, etc. in a small area of land, which can help the town planners, besides its appearance and glory. However, for many cosmopolitans, high-rise buildings are the only response to the continuous growth of population concentration. The purpose of constructing high-rise buildings is to use more area to meet the needs of different citizens. This is a way to save on land use and share prices to users, thus avoiding the unnecessary land use, coping with its scarcity, and expanding urban

Mohsen Malekinejad

m.malekinejad@iausirjan.ac.ir

Seyed Mozafar Davari

sm_davari@iauk.ac.ir

Reza Rahgozar

rahgozar@uk.ac.ir

1 Civil Engineering Department, Islamic Azad University, Sirjan Branch, Sirjan, Iran

2 Young Researchers and Elite Club, Islamic Azad University, Sirjan Branch, Sirjan, Iran

3 Civil Engineering Department, Shahid Bahonar University of Kerman, Kerman, Iran levels. The conventional analysis of tall structures is often time-consuming and costly due to having high degrees of freedom. The designers of this kind of buildings require a proper and reasonable design for their design and it is necessary to be able to analyze the static and dynamic characteristics of the structure quickly and accurately. Additionally, the effect of each variable in assumed structural system should be determined and finally, the first appropriate design should be recommended. Considering the importance of framed tube structures in high-rise buildings as a system resistant to lateral loads, it is necessary to have a simple but precise method for analyzing these structures.

There are different forms of tall buildings and numerous researches have been carried out about the approximate and exact methods of investigating the behaviour, deflection, vibration, optimal design and control of such buildings. Coull and Bose (1975) presented a method based on the theory of elasticity. In this method, the structure is equivalent to orthotopic planes, and the equations and equilibrium relations are satisfied in the equivalent structure. Coull and Ahmed (1978) presented a method in calculation of stories displacement in the framed tube. Kwan (1994) presented equations for determining the stress in columns and obtaining the lateral displacement of the framed tube structure using equivalence orthotropic planes, energy relations and the theory of elasticity. Connor and 
Pouangare (1991) recommended the five-stringer model, in which the structure is equalled with beams and vertical planes and by calculating the shear and moment rigidity of members, the formulas for stresses in the column are proceeded. One of the other methods for improving the behavior of the framed tube is adding internal tubed frames to the original structure. In this case, the stress distribution and displacement will be appreciably reduced. Other methods for analyzing framed-tube are presented by researchers such as Paulino (2010), Mahjub et al. (2011), Kamgar and Rahgozar (2013), Rahgozar et al. (2014), Malekinejad and Rahgozar (2014), Mohammadnejad (2015), Rahgozar et al. (2015), Khajuai Rad et al. (2017). A parametric dimensionless formula has been developed for flexural stiffness of high-rise buildings with the objective of optimization problem by Alavi et al. (2017). Kamgar and Rahgozar (2019) introduced a method to reduce the static roof displacement and axial forces in the columns of tall buildings. Tavakoli et al. (2019) considered a direct method for high-rise structures with elastic and inelastic analysis with fixed-base system. Davari and Rahgozar (2019) conducted their research on the static analysis of high-rise buildings without shear lag effect, too. Davari et al. (2019) explained the Euler-Bernoulli and the Timoshenk's beam theory to analyse the tall buildings, which it concluded that the Timoshenko theory is more accurate than the Euler-Bernoulli. In this paper, a simple approximation method has been proposed for static analysis of a tall structure with a framed tube system with symmetrical plan and fixed profile in height using a Timoshenko beam model with regard to shear and flexural hardening and regardless of the shear lag effects (Herrmann 1955). Finally, a revised formula for the shape factor of the high-rise buildings is proposed to minimize the error between ETABS modeling and the Timoshenko's theory.

\section{Method}

In this study, the framed tube was equalized with four orthotropic orthogonal planes with a hollow box section, the structure of the framed tube was subjected under a uniform load and triangular distributed loading, and static analysis was performed. Davari et al. presented the Euler-Bernoulli's theory and the Timoshenko's beam theory to calculate the displacement of the stories.

\section{Uniform distributed loading}

Equations 1 and 2 show the displacement of the structure at the distance of $x$ from the bottom of the structure for the Euler-Bernoulli and the Timoshenko theories, respectively.

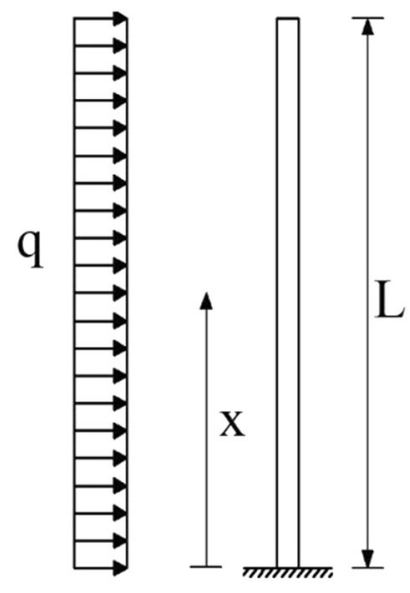

Fig. 1 Analysis model of structure under uniform distributed loading pattern

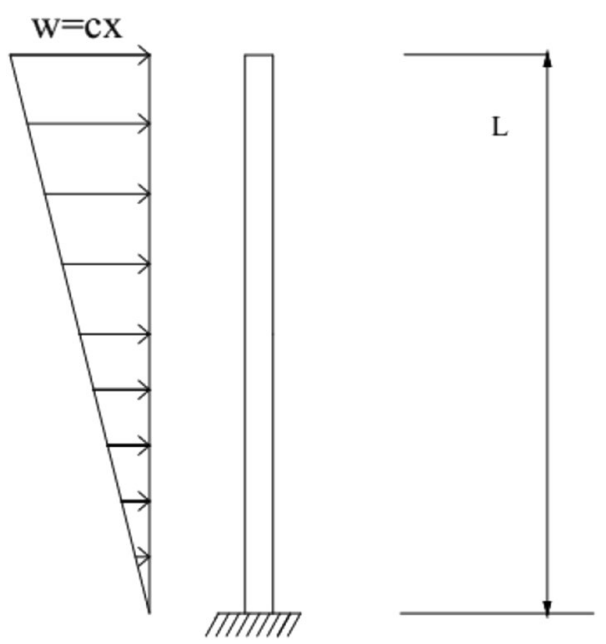

Fig. 2 Analysis model of structure subjected to triangular loading pattern

$\omega(x)=\frac{q}{E I}\left(\frac{L^{2} x^{2}}{4}-\frac{L x^{3}}{6}+\frac{x^{4}}{24}\right)$

$\omega(x)=\frac{q}{E I}\left(\frac{L^{2} x^{2}}{4}-\frac{L x^{3}}{6}+\frac{x^{4}}{24}\right)+\frac{q l x-q x^{2} / 2}{k A G}$

In the above equations, $q$ is the uniform loading pattern, $L$ is the height of the structure and $x$ is the distance from the bottom of the structure (see Fig. 1). Moreover, the parameters $E, G, I, k$ and $A$ are Young's modulus of the material, shear modulus of the material, moment of the inertia, shape factor and area of the section, respectively. 


\section{Triangular distributed loading}

When the structure is subjected to a triangular loading pattern in accordance with Fig. 2, the angle of rotation of the different points at the height of the structure is equal to $\varphi$ and the lateral displacement is equal to $\omega$.

In this loading pattern, $M_{x}$ can be written as:

$M_{x}=\frac{c L^{2} x}{2}-\frac{c L^{3}}{3}-\frac{c x^{3}}{6}$.

Using Eq. 3, it will be concluded:

$$
\begin{aligned}
E I \frac{\mathrm{d}^{2} \omega}{\mathrm{d} x^{2}} & =\frac{c L^{2} x}{2}-\frac{c L^{3}}{3}-\frac{c x^{3}}{6} \\
\varphi(x) & =\frac{\mathrm{d} \omega}{\mathrm{d} x}=\frac{c}{E I}\left(\frac{L^{2} x^{2}}{4}-\frac{L^{3} x}{3}-\frac{x^{4}}{24}\right)+c_{1} .
\end{aligned}
$$

By applying boundary condition on Eq. 4, the constant will be:

$\varphi(0)=0 \Rightarrow c_{1}=0$.

So:

$\varphi(x)=\frac{c}{E I}\left(\frac{L^{2} x^{2}}{4}-\frac{L^{3} x}{3}-\frac{x^{4}}{24}\right)$.

Using Eq. 6, $\omega(x)$ will be calculated in Eq. 7:

$$
\begin{aligned}
\omega(x) & =\int \varphi(x) \mathrm{d} x \\
& =\frac{c}{E I}\left(\frac{L^{2} x^{3}}{12}-\frac{L^{3} x^{2}}{6}-\frac{x^{5}}{120}\right)+c_{1} .
\end{aligned}
$$

By applying another boundary condition, the constant of integration will be obtained:

$\omega(0)=0 \Rightarrow c_{1}=0$.

Overall, the displacement formula will proceed in Eq. 9:

$\omega(x)=\frac{c}{E I}\left(\frac{L^{2} x^{3}}{12}-\frac{L^{3} x^{2}}{6}-\frac{x^{5}}{120}\right)$.

In the following, two examples are presented to examine the proposed method and compare the results of the numerical investigation with two others theories. Each of these structures has been analyzed and studied with ETABS modeling, proposed method and Euler-Bernoulli's theory under a uniform static load pattern.

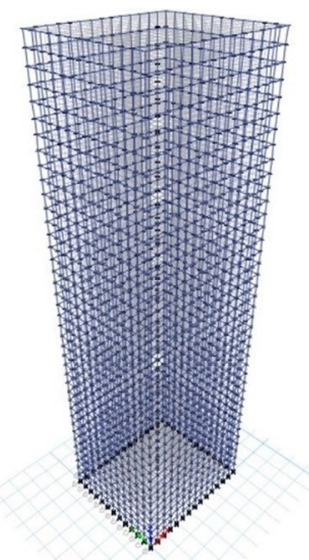

(a)

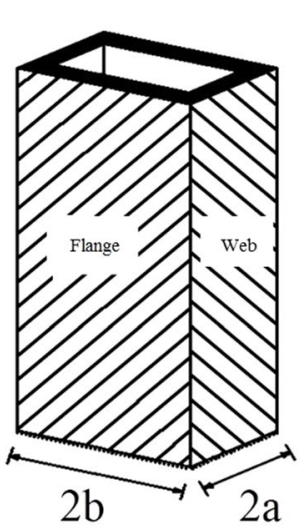

(b)
Fig. 3 Framed-tube system: a actual structure, b equivalent structure (Khajouyi Rad et al. 2017)

\section{Concrete framed-tube with symmetric plan}

The structure of a 40-storey concrete frame with a symmetrical plan has been used and statically analyzed (Fig. 3) (Kwan 1994). The overall dimensions of the structure are $35 \mathrm{~m} \times 30 \mathrm{~m}$. The distance between the columns is $2.5 \mathrm{~m}$ and the height of each storey is $3 \mathrm{~m}$. In this structure, dimensions of all beams and columns are $0.8 \times 0.8 \mathrm{~m}$ and Young's modulus and shear modulus of the materials are $200 \mathrm{GPa}$ and $8 \mathrm{GPa}$, respectively. In addition, a uniform loading pattern $(120 \mathrm{kN} / \mathrm{m})$ is applied to the structure for calculating the deformation of the structure.

For numerical analysis, we considered the values of some parameters given for a Timoshenko beam in a uniformly loading pattern, as the following (Table 1). As it is obvious from Fig. $1 \mathrm{~b}$, the $a$ and $b$ are the half of the length and the width of the plan of the high-rise building. The parameter $t$ is the equivalent thickness of the plan of the structure which will be calculated based on the formula that presented in Table $1 . A_{\mathrm{c}}$ and the $S$ are the column area section and the distances between them. $k$ and $I$ are the shape factor and the section modulus of the box section. $\Delta_{\mathrm{b}}$ and $\Delta_{\mathrm{c}}$ are the deflection induced by bending and the shear, respectively. $Q$ is defined as lateral loading pattern, too. Moreover, all parameters are described in Hutchinson research (Hutchinson 2001). The mentioned parameters will be equal to Table 1 .
Table 1 Parameters of equivalent structure

\begin{tabular}{llllll}
\hline$t=\frac{A_{\mathrm{c}}}{S}$ & $I=4 a^{2} b t+\frac{4}{3} a^{3} t$ & $k$ & $\frac{\Delta_{\mathrm{b}}}{Q}=\frac{\left(h-d_{\mathrm{b}}\right)^{3}}{12 E_{\mathrm{m}} I_{\mathrm{c}}}+\left(\frac{h}{S}\right)^{2} \frac{\left(S-d_{\mathrm{c}}\right)^{2}}{12 E_{\mathrm{m}} I_{\mathrm{b}}}$ & $\frac{\Delta_{\mathrm{s}}}{Q}=\frac{\left(h-d_{\mathrm{b}}\right)}{G_{\mathrm{m}} A_{\mathrm{sc}}}+\left(\frac{h}{S}\right)^{2} \frac{\left(S-d_{\mathrm{c}}\right)}{G_{\mathrm{m}} A_{\mathrm{sb}}}$ & $G=\frac{\frac{h}{S t}}{\frac{\Delta_{\mathrm{b}}}{Q}+\frac{\Delta_{\mathrm{s}}}{Q}}$ \\
\hline $0.26 \mathrm{~m}$ & $5184 \mathrm{~m}^{4}$ & $\frac{5}{6}$ & $2.1634 \times 10^{-9}$ & $0.9078 \times 10^{-9}$ & $1.526 \mathrm{GPa}$ \\
\hline
\end{tabular}




\section{Results}

To compare the results of above methods, including ETABS modeling, Euler-Bernoulli and Timoshenko methods, once a 40-storey concrete structure with symmetric plan and then an 80-storey like the previous one had been modeled in ETABS and the displacement at top of the structure have been compared. Figure 4 shows the displacement of stories for the three proposed methods of a 40-storey building.

Based on mean square displacement (MSD) by the ETABS modeling compared to Bernoulli method is about $82 \%$, and it was $45 \%$ with the Timoshenko method. Figure 5 shows the stories displacement for the three proposed methods for a 80-storey building. The MSD of Bernoulli's method and the ETABS is $54 \%$, which is about $31 \%$ for the proposed method with ETABS modeling.

As can be seen from Eq. 2, the value of displacement is related to the three main parameters of $k, G$ and $A$, which can be evaluated by changing some geometric characteristics of the structure. Doing so, the structure is firstly modeled in both concrete and steel structures, and the

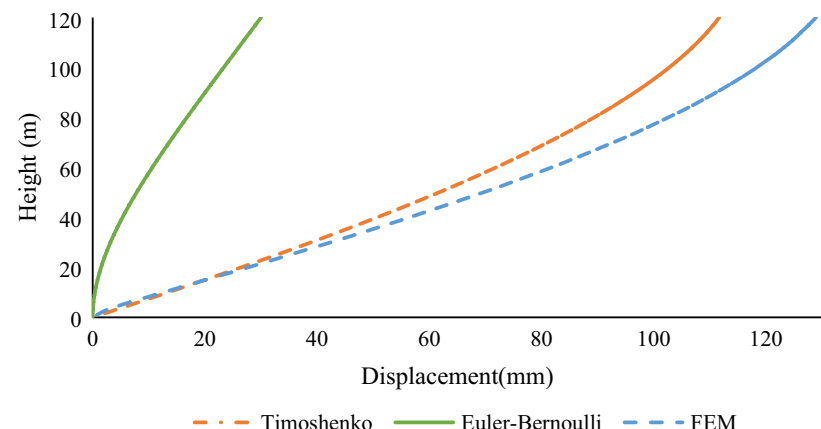

Fig. 4 Comparison of displacement obtained by three proposed methods for a 40-storey concrete building

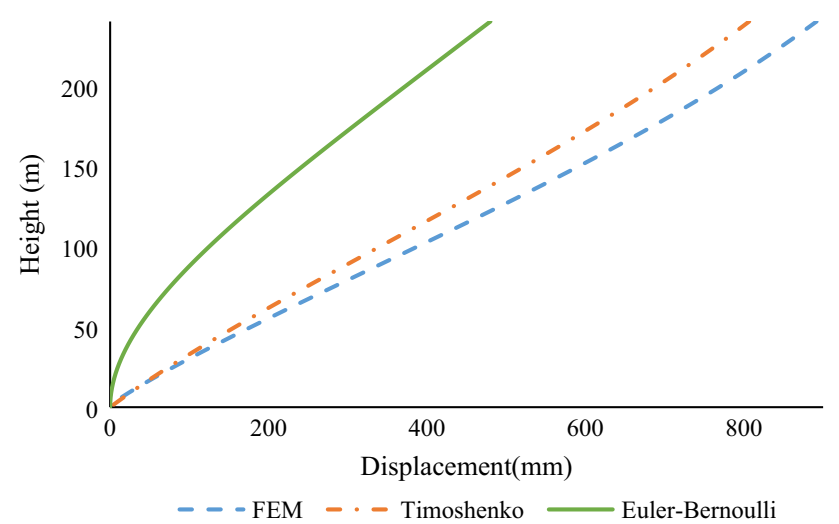

Fig. 5 Comparison of displacement obtained by three presented methods for an 80-storey concrete building
Table 2 Lateral displacements calculated in different area of concrete structure

\begin{tabular}{lllc}
\hline $\begin{array}{l}\text { Area of concrete } \\
\text { structure }\left(\mathrm{m}^{2}\right)\end{array}$ & $\begin{array}{l}\text { ETABS mod- } \\
\text { eling }(\mathrm{mm})\end{array}$ & $\begin{array}{l}\text { Timoshenko } \\
(\mathrm{mm})\end{array}$ & Error $(\%)$ \\
\hline 750 & 496.6 & 451.2 & 9.14 \\
1050 & 354 & 292.1 & 17.49 \\
1400 & 299.5 & 201.8 & 32.62 \\
1800 & 260.7 & 146.4 & 43.84 \\
\hline
\end{tabular}

Table 3 Lateral displacements calculated in concrete structure with different heights of the stories

\begin{tabular}{lllc}
\hline $\begin{array}{l}\text { Height of concrete } \\
\text { structure's stories } \\
(\mathrm{m})\end{array}$ & $\begin{array}{l}\text { ETABS } \\
\text { modeling } \\
(\mathrm{mm})\end{array}$ & Timoshenko (mm) & Error $(\%)$ \\
\hline 3 & 354 & 292.1 & 17.49 \\
3.5 & 584 & 534.2 & 8.53 \\
4 & 908 & 839.7 & 7.52 \\
4.5 & 1347.5 & 1266.2 & 6.03 \\
5 & 1925.8 & 1844 & 4.25 \\
\hline
\end{tabular}

Table 4 Lateral displacements calculated in different area of steel structure

\begin{tabular}{lllr}
\hline $\begin{array}{l}\text { Area of steel } \\
\text { structure }\left(\mathrm{m}^{2}\right)\end{array}$ & $\begin{array}{l}\text { ETABS mod- } \\
\text { eling }(\mathrm{mm})\end{array}$ & $\begin{array}{l}\text { Timoshenko } \\
(\mathrm{mm})\end{array}$ & Error $(\%)$ \\
\hline 750 & 265.4 & 258.3 & 2.68 \\
1050 & 214 & 176.8 & 17.38 \\
1400 & 185.5 & 128.2 & 30.89 \\
1800 & 165.8 & 116.4 & 29.79 \\
\hline
\end{tabular}

Table 5 Lateral displacements calculated in different areas of steel structure

\begin{tabular}{lllc}
\hline $\begin{array}{l}\text { Height of steel struc- } \\
\text { ture's stories }(\mathrm{m})\end{array}$ & $\begin{array}{l}\text { ETABS mod- } \\
\text { eling }(\mathrm{mm})\end{array}$ & $\begin{array}{l}\text { Timoshenko } \\
(\mathrm{mm})\end{array}$ & Error $(\%)$ \\
\hline 3 & 214 & 212.2 & 0.84 \\
3.5 & 332.5 & 317.6 & 4.48 \\
4 & 493.8 & 458.2 & 7.21 \\
4.5 & 706.3 & 642.2 & 9.08 \\
5 & 1052 & 878.7 & 16.47 \\
\hline
\end{tabular}

parameter $G$, which represents the shear modulus, and is investigated by changing the height of the stories. In addition, changes have been made to the dimensions of the architectural plan to obtain the parameters $k$ and $A$, which represent the shape factor and area of the plan, respectively. The height of the floors structures was considered in five different conditions including $3,3.5,4$, 


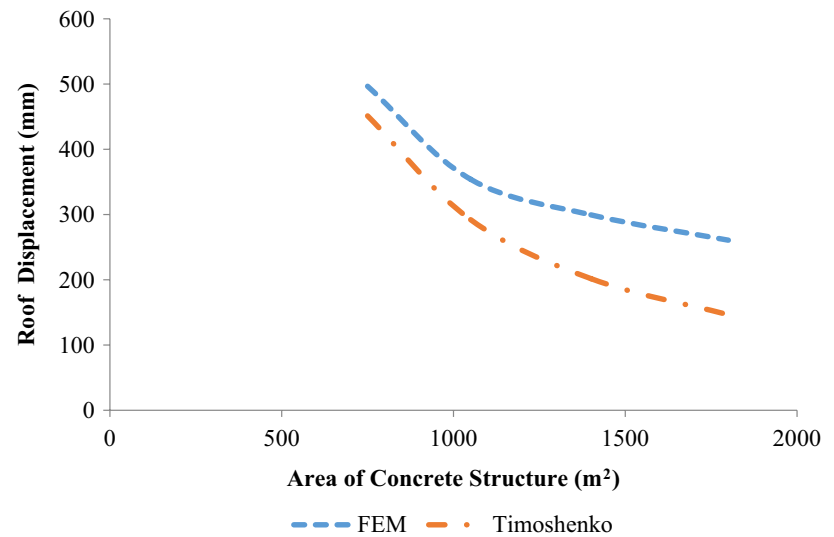

Fig. 6 Displacement of proposed method and FEM for 40-storey concrete structure with different areas in plan

4.5 and $5 \mathrm{~m}$ to study the shear modulus. The plan dimensions in the values of $25 \times 30 \mathrm{~m}, 30 \times 35 \mathrm{~m}, 35 \times 40 \mathrm{~m}$ and $40 \times 45 \mathrm{~m}$ have been changed to examine the shape factor and area of the plan. The results of concrete structure are presented in Tables 2 and 3, and the results of the steel structure, have been represented in Tables 4 and 5. Figures 6, 7, 8 and 9 represent the area effect and height of the stories in concrete and steel structure, respectively.

As can be seen from Figs. 7 and 9, it could be concluded that with the change in the height of the stories, there is not much difference between the displacements obtained from the two methods for the highest point of the structure. Moreover, on the other hand, this variation in height changes the modulus parameter shear, $G$, so it can be concluded that the shear-modulus changes do not affect the difference in the results of the two methods. Based on Figs. 6 and 8, it could be stated that by changing the dimensions of the plan, there is a greater difference between the displacements obtained from the two methods for the highest point of the structure relative to the changes in the shear modulus in the previous state. Additionally, the area of each floor, $A$, changes the coefficient of the parameter $k$, so it could be concluded that area
Fig. 7 Displacement of proposed method and FEM for 40 -storey concrete structure with varying storey's height

Fig. 8 Displacement of proposed method and FEM for the 40-storey steel structure with different areas in plan
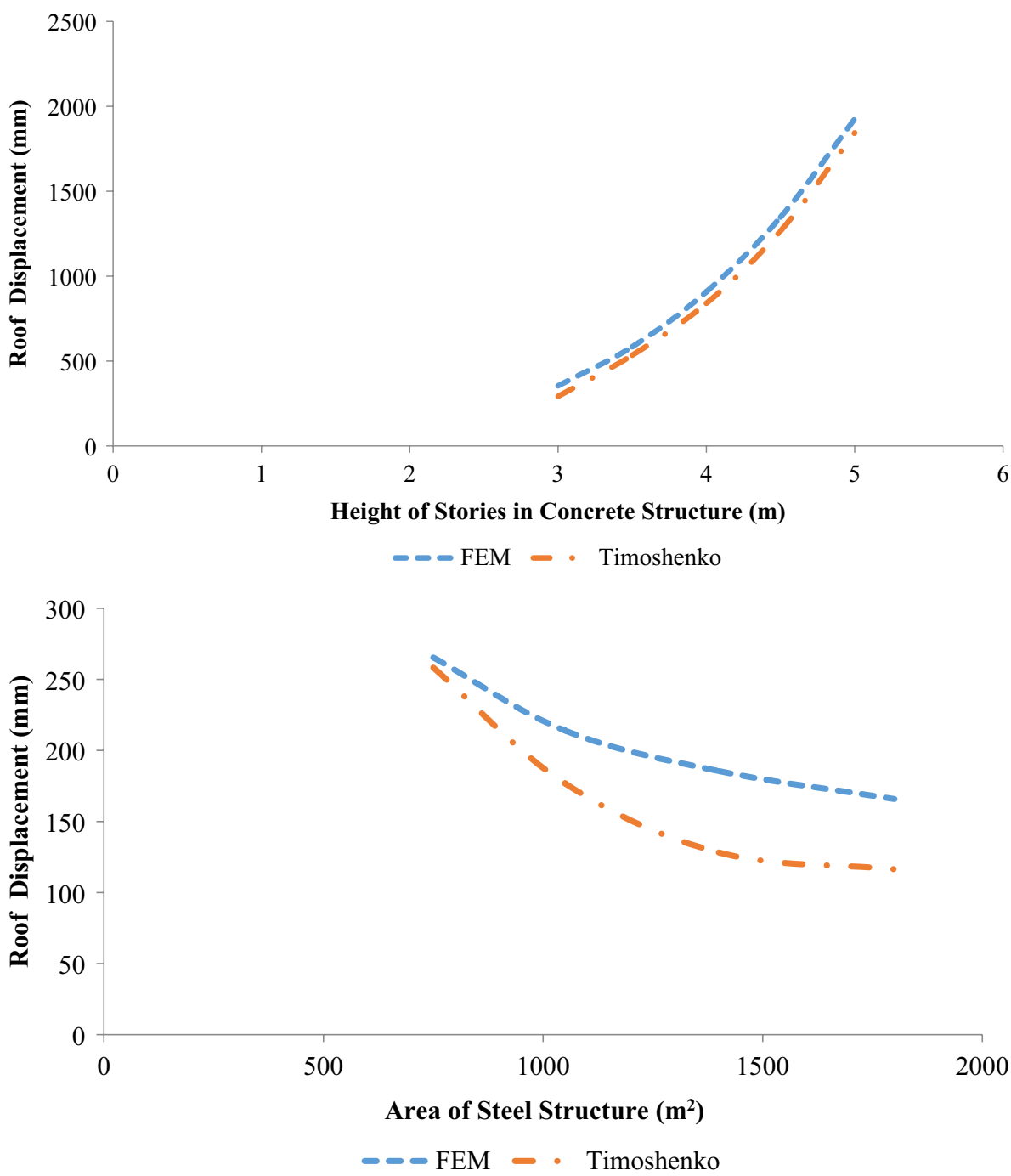
Fig. 9 Displacement of proposed method and FEM for a 40 -storey building with varying storey height

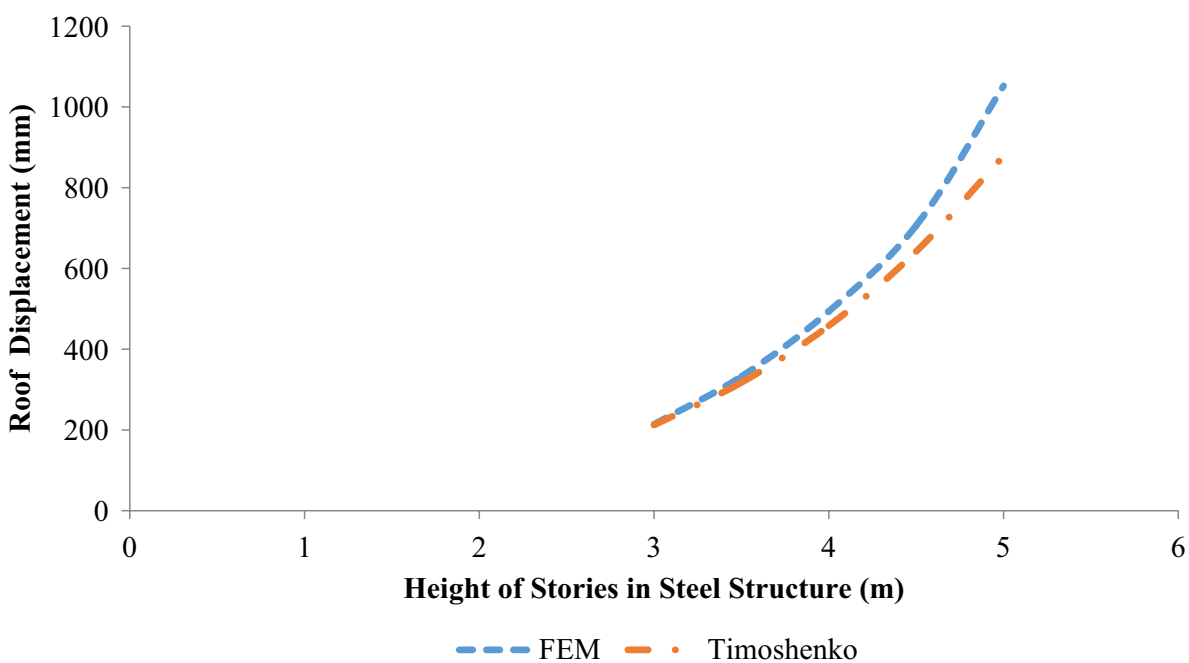

Table 6 Comparison of results for shape factor and displacement

variations have a greater effect on the difference in the results of the two methods. By varying the values of the parameters $a$ and $b$, we can obtain an equation for parameter $k$, which gives us a more precise amount of displacement in the theoretical method. For this purpose, various amounts of $k$ have been checked in the formulation of the proposed method to achieve the nearly displacement, which is obtained from ETABS modeling, then this procedure is repeated for all of the models. Therefore, a series of numbers obtained by it for parameter $k$, the relation formula with $a$ and $b$ will be developed by solving this function. The Eq. 10 shows the $k$ formula that is based on Hutchinson research (Alavi et al. 2017) for the rectangular cross section. The parameter $C_{4}$ in Eq. 11 is also revised like Eq. 10. In fact, calculation of the displacement for the tall structures is simplified by these changes.

$k=-\frac{0.0034(1+v)}{\left[0.0715 \frac{C_{4}}{a^{5} b}+v \times 0.3948\left(1-\frac{b^{2}}{a^{2}}\right)\right]}$

$C_{4}=\frac{4}{45} a^{3} b\left(-12 a^{2}-15 v a^{2}+5 v b^{2}\right)$

To investigate the accuracy of the proposed equation, a $20 \times 25 \mathrm{~m}$ planar concrete structure was modeled in ETABS software and the output results were obtained. On the other hand, we extracted the same output from the theoretical method with $k$ value obtained from the formula presented above. According to the results, obtained $k$ value had an acceptable accuracy. Table 6 indicates the results of the ETABS modelling, proposed method by $k=\frac{5}{6}$ and the proposed method by Eq. 10 .

\begin{tabular}{lll}
\hline Analysis type & Shape factor & $\begin{array}{l}\text { Displace- } \\
\text { ment } \\
(\mathrm{mm})\end{array}$ \\
\hline ETABS & - & 567.3 \\
Old proposed method & 0.83 & 642.6 \\
New proposed method & 1.7 & 571.4 \\
\hline
\end{tabular}

\section{Conclusion}

- Proposed model for the analysis of tall structures with symmetrical plan produced acceptable results, particularly in the initial design stage.

- Although numerical methods and commercial software were more accurately able to model tall structures, the analytical approach presented in the proposed method provided the ability to determine the parameters affecting structure behavior and their sensitivity analysis in the structure response.

- Proposed method was less costly compared to the numerical methods such as finite element, and required less computing procedures. This issue becomes more important in the case of high-rise structures with a large number of elements.

- New coefficients for the shape factor equation induced better accuracy for the displacement of the framed-tube structures.

- Besides the accuracy of the shape factor equation for the framed-tube structures, the time-consuming analysis could be reduced significantly.

- The results of the analysis with shear effect is considerable because Timoshenko beam theory adapted vigorously on the ETABS modeling results. 
Open Access This article is distributed under the terms of the Creative Commons Attribution 4.0 International License (http://creativeco mmons.org/licenses/by/4.0/), which permits unrestricted use, distribution, and reproduction in any medium, provided you give appropriate credit to the original author(s) and the source, provide a link to the Creative Commons license, and indicate if changes were made.

\section{References}

Alavi A, Rahgozar R, Torkzadeh P, Hajabasi MA (2017) Optimal design of high-rise buildings with respect to fundamental eigenfrequency. Int J Adv Struct Eng 9(4):365-374

Connor JJ, Pouangare CC (1991) Simple model for design of framed tube structures. J Struct Eng ASCE 117:3623-3644

Coull A, Ahmed K (1978) Deflection of framed-tube structures. J Struct Eng ASCE 104:857-862

Coull A, Bose B (1975) Simplified analysis of frame tube structures. J Struct Div 101:2223-2240

Davari SM, Rahgozar R (2019) The static analysis of high-rise buildings with framed-tube system based on Timoshenko beam theory without shear lag effect. In: The 4th international conference on urban management. Civil Engineering \& Technology in Modern Architecture, Paris

Davari SM, Rahgozar R, Maleknejad M (2019) A simple method for static analysis of tubular high-rise buildings using Timoshenko beam theory. Int J Eng Technol 11(3):563-575

Herrmann G (1955) Forced motions of Timoshenko beams. J Appl Mech Trans ASME 22(2):53-56

Hutchinson JR (2001) Shear coefficients for Timoshenko beam theory. J Appl Mech 68(1):87-92

Kamgar R, Rahgozar R (2013) A simple approximate method for free vibration analysis of framed tube structures. Struct Des Tall Spec Build 22(2):217-234

Kamgar R, Rahgozar P (2019) Reducing static roof displacement and axial forces of columns in tall buildings based on obtaining the best locations for multi-rigid belt truss outrigger systems. Asian J Civ Eng. https://doi.org/10.1007/s42107-019-00142-0
Khajouyi Rad M, Alavi S, Rahgozar R (2017) Optimum location of outrigger-belt truss in tall buildings based on energy method in hybrid systems. In: The 5th international congress of civil engineering, Shahid Beheshti University, Tehran

Kwan AKH (1994) Simple method for approximate analysis of framedtube structures. J Struct Eng ASCE 120:1221-1239

Mahjoub R, Rahgozar R, Saffari H (2011) Simple method for analysis of tube frame by consideration of negative shear lag. Aust J Basic Appl Sci 5(3):309-316

Malekinejad M, Rahgozar R (2014) An analytical model for dynamic response analysis of tubular tall buildings. Struct Des Tall Spec Build J 23(1):67-80

Mohammadnejad M (2015) A new analytical approach for determination of flexural, axial and torsional natural frequencies of beams. Struct Eng Mech 55(3):655-674. https://doi.org/10.12989 /sem.2015.55.3.655

Paulino MR (2010) Preliminary design of tall buildings. MSc Thesis, Civil and Environmental Engineering Department, Worcester Polytechnic Institute, Worcester

Rahgozar R, Ahmadi AR, Ghelichi M, Goudarzi Y, Malekinejad M, Rahgozar P (2014) Parametric stress distribution and displacement functions for tall buildings under lateral loads. Struct Des Tall Spec Build J 23(1):22-41

Rahgozar R, Mahmoudzadeh Z, Malekinejad M, Rahgozar P (2015) Dynamic analysis of combined system of framed tube and shear walls by Galerkin method using B-Spline functions. Struct Des Tall Spec Build J 24(8):591-606

Tavakoli R, Kamgar R, Rahgozar R (2019) Seismic performance of outrigger belt truss system considering soil-structure interaction. Int J Adv Struct Eng 11(1):45-54. https://doi.org/10.1007/s4009 $-019-0215-7$

Publisher's Note Springer Nature remains neutral with regard to jurisdictional claims in published maps and institutional affiliations. 